\title{
FATORES PSICOSSOCIAIS ENFRENTADOS POR GRÁVIDAS NA FASE FINAL DA ADOLESCÊNCIA
}

\section{Psychosocial factors faced by pregnant women in late adolescence \\ Factores psicosociales afrontados por embarazadas en la fase final de la adolescencia}

\section{Gleiciane Fontenele Costa}

Instituto Superior de Tecnologia Aplicada - INTA - Sobral (CE) - Brasil

\section{Danielle D’ávila Siqueira}

Instituto Superior de Tecnologia Aplicada - INTA- Sobral (CE) - Brasil

\section{Francisca Alanny Araújo Rocha}

Instituto Superior de Tecnologia Aplicada - INTA- Sobral (CE) - Brasil

Universidade de Fortaleza - UNIFOR - Fortaleza (CE) - Brasil

\section{Francisca Bertilia Chaves Costa}

Universidade de Fortaleza - UNIFOR - Fortaleza (CE) - Brasil

\section{July Grassiely de Oliveira Branco}

Universidade de Fortaleza - UNIFOR - Fortaleza (CE) - Brasil

\section{RESUMO}

Objetivo: Conhecer os fatores psicossociais enfrentados por adolescentes grávidas atendidas em uma Unidade de Atenção Primária à Saúde. Métodos: Pesquisa exploratória e descritiva, com abordagem qualitativa, realizada através de grupo focal, em dezembro de 2015, em uma cidade da zona Norte do estado do Ceará. Participaram deste estudo oito gestantes com idade entre 18 e 19 anos. A análise apresentou-se, na modalidade temática, com as seguintes categorias: Razões para engravidar e sentimentos vivenciados pelas adolescentes; Apoio familiar e profissional versus preconceito; Mudanças positivas versus dificuldades enfrentadas. Resultados: Os achados desvelam que as razões da ocorrência da gravidez variaram desde a falta de contracepção até a confiança de que não iriam engravidar. Além disso, no que tange à rede de apoio social, os enfermeiros foram os profissionais mais citados. Quanto às mudanças positivas, evidenciaram maior aproximação da família e do companheiro; já as dificuldades enfrentadas são referentes a não conseguir manter os estudos. Conclusão: Emergiram sentimentos de rejeição, tristeza e angústia oriundos de uma gravidez indesejada e ao grande impacto na vida psicológica das adolescentes.

Descritores: Adolescente; Gravidez na Adolescência; Saúde Pública.

\section{ABSTRACT}

Objective: To know the psychosocial factors faced by pregnant adolescents attending a Primary Health Care Center. Methods: Qualitative exploratory and descriptive study carried out using a focus group in December 2015 in a city in Northern Ceará. Participants were eight pregnant women aged 18 to 19 years. Thematic analysis was performed and the following categories emerged: Reasons for getting pregnant and feelings experienced by adolescents; Family and professional support versus prejudice; Positive changes versus difficulties faced. Results: The findings reveal that the reasons for getting pregnant ranged from lack of contraception to believing that they would not get pregnant. In addition, nurses were the most cited professionals regarding the social support network. As for positive changes, closer relationships with the family and partner stood out. With regard to the difficulties faced, these are related to not being able to continue their education. Conclusion: Feelings of rejection, sadness and anguish emerged from an unwanted pregnancy and its huge impact on the psychological well-being of adolescents.

Descriptors: Adolescent; Pregnancy in Adolescence; Public Health. 


\section{RESUMEN}

Objetivo: Conocer los factores psicosociales afrontados por adolescentes embarazadas asistidas en una Unidad de Atención Primaria de Salud. Métodos: Investigación exploratoria y descriptiva de abordaje cualitativo realizada a través de grupo focal en diciembre de 2015 en una ciudad de la zona norte del estado de Ceará. Ocho embarazadas con edad entre 18 y 19 años participaron del estudio. El análisis se dio por temática con las siguientes categorias: Razones para quedarse embarazada y sentimientos vividos por las adolescentes; Apoyo familiar y profesional versus prejuicio; Cambios positivos versus dificultades afrontadas. Resultados: Los hallazgos desvelan que las razones para el embarazo variaron desde la falta de contracepción hasta la confianza de que no iban a quedarse embarazadas. Además, respecto la red de apoyo social, los enfermeros fueron los profesionales más citados. Sobre los cambios positivos, se evidenció mayor cercanía de la familia y de la pareja; respecto las dificultades afrontadas estas se refieren al no seguimiento de los estudios. Conclusión: Emergieron sentimientos de rechazo, tristeza y angustia oriundos de un embarazo no deseado y a su gran impacto en la vida psicológica de las adolescentes.

Descriptores: Adolescente; Embarazo en Adolescencia; Salud Pública.

\section{INTRODUÇÃO}

A adolescência é a fase da vida compreendida entre a infância e a idade adulta, marcada por um complexo processo de crescimento e desenvolvimento biopsicossocial. Considera-se adolescência a segunda década da vida, que vai dos 10 aos 19 anos, identificando adolescentes jovens àqueles que se encontram entre 15 e $19 \operatorname{anos}^{(1)}$.

O ser humano, ao chegar à adolescência, sofre alterações corporais, as quais levam à capacidade reprodutiva. Com isso, fazse necessário compreender sua sexualidade, as mudanças corporais, saber prevenir-se de situações que possam vir a redirecionar seus projetos de vida, como infecções sexualmente transmissíveis, aborto, maternidade e paternidade sem planejamento. Destaca-se que a falta de orientação sexual na escola e na família e a vulnerabilidade social levam o adolescente à prática sexual desprotegida ${ }^{(2)}$. Dessa forma, é necessário investir em educação sexual, não apenas para orientações quanto a práticas sexuais, mas para proporcionar a conscientização de uma vida com atitudes responsáveis ${ }^{(3)}$.

Uma das principais consequências da prática sexual desprotegida é a gravidez indesejada, acarretando alterações na dinâmica familiar ${ }^{(2)}$. A cada ano nascem cerca de 14 milhões de crianças de mães adolescentes em todo o mundo. A taxa de fecundidade de adolescentes no Caribe e América Latina é de 73,2 por mil nascimentos ${ }^{(4)}$. Em nível de Brasil, observa-se um índice de 65 gestações para cada um mil meninas de 15 a 19 anos, segundo dados referentes ao período de 2006 a 2015 avaliados pelo Fundo de População das Nações Unidas ${ }^{(5)}$.

Ademais, as modificações psicossociais oriundas da gestação estão relacionadas à evasão escolar, menor chance de qualificação profissional, medos e preocupações, adiamento de metas para o futuro, privação da adolescência, afastamento de amigos e familiares, e mudanças no estilo de $\operatorname{vida}^{(6)}$.

Compreende-se que a promoção da saúde é caracterizada pelo processo de empoderamento dos indivíduos para que possam desenvolver ações coletivas que impactem positivamente na qualidade de vida e saúde, galgando um completo bem-estar físico, mental e social ${ }^{(7)}$. Neste contexto, o suporte social recebido pela gestante adolescente reverbera favoravelmente na prevenção de alterações psicossociais ${ }^{(8)}$.

Constitui-se relevante agrupar um conjunto de informações sobre a realidade vivenciada pelas adolescentes grávidas, assim como as mudanças psicossociais enfrentadas no contexto familiar e na comunidade, para subsidiar a elaboração de estratégias que atendam às reais necessidades dessas adolescentes, dando ênfase na promoção de saúde e prevenção de agravos. Diante disto, objetivou-se conhecer os fatores psicossociais enfrentadas por adolescentes grávidas atendidas em uma Unidade de Atenção Primária à Saúde (UAPS).

\section{MÉTODOS}

Trata-se de uma pesquisa exploratória-descritiva, de abordagem qualitativa, desenvolvida em uma Unidade de Atenção Primária à Saúde situada na região norte do Ceará, em dezembro de 2015.

Os critérios de inclusão utilizados para a amostra foram: ser adolescente, estar grávida e em acompanhamento pré-natal na UAPS referida para o estudo, assim como também se fazer presente no dia do encontro agendado para a coleta de dados do estudo. Como critério de exclusão: gestantes que desenvolvessem complicações durante o período gestacional que as impedissem de participar da pesquisa. Diante desses critérios houve a possibilidade de captação de oito adolescentes grávidas, referente ao total de gestantes correspondentes ao período de realização do estudo e que aceitaram voluntariamente participar, sendo estas compreendidas na faixa etária de 18 e 19 anos e cadastradas nessa unidade de saúde.

Para a realização da coleta de informações, utilizou-se a técnica do grupo focal. Este método insere-se em pesquisas qualitativas para a busca de dados que se dão por meio de interações coletivas ${ }^{(9)}$. O convite para a participação do estudo foi feito pelas enfermeiras e pelos agentes comunitários de saúde (ACS) a todas as gestantes adolescentes cadastradas. 
No dia previsto para realização do grupo focal, oito adolescentes compareceram, e para elas foram relatados os objetivos do estudo e a técnica que seria utilizada na pesquisa, apresentando-lhes o Termo de Consentimento Livre e Esclarecido (TCLE), o qual fora lido e assinado, garantindo a sua participação. A literatura refere uma variação de seis a 15 participantes em grupos focais $^{(10)}$.

As gestantes presentes foram reunidas em uma sala isenta de ruídos e interrupções, o que permitiu o uso de gravadores. As cadeiras foram dispostas circularmente de forma que cada participante tinha a visão das demais pessoas presentes no momento do grupo. A condução do grupo foi feita por uma moderada e uma relatora, que nortearam a realização desse momento a partir de temas disparadores relacionados às repercussões psicossociais da gravidez na adolescência e ao período gestacional e à rede de apoio social. Entretanto, antes do início do grupo focal, todas as adolescentes, além da assinatura do TCLE, responderam a um questionário para caracterização do perfil socioeconômico.

Os relatos das participantes foram gravados e transcritos na íntegra. Para a análise e interpretação das informações, utilizou-se a análise temática, a qual se desdobra em três etapas: a) pré-análise, constituída pela escolha dos documentos a serem analisados e na retomada de hipóteses e dos objetivos iniciais da pesquisa; b) exploração do material, caracterizada por uma operação classificatória que visou alcançar o núcleo de compreensão do texto e c) tratamento dos resultados obtidos e sua interpretação ${ }^{(9)}$.

Com o intuito de salvaguardar a identidade das participantes, utilizaram-se identificações G1, G2, (...Gn) fazendo alusão ao termo gestante e a ordem crescente de relatos, a fim de manter o anonimato das mesmas.

A presente pesquisa atendeu aos preceitos éticos contidos na Resolução 466/12 do Conselho Nacional de Saúde ${ }^{(11)}$, recebendo aprovação pelo Comitê de Ética em Pesquisa da Universidade Estadual Vale do Acaraú - UVA sob Parecer nº 1.344.070.

\section{RESULTADOS}

O corpus da pesquisa deu-se em conformidade com o objetivo proposto pelo estudo. A apresentação dos resultados constituiuse, inicialmente, pela caracterização das participantes, seguida pelo tratamento das informações e a organização dos conteúdos, emergindo as seguintes categorias: Razões para engravidar e sentimentos vivenciados pelas adolescentes; Apoio familiar e profissional versus preconceito; Mudanças positivas versus dificuldades enfrentadas.

A população participante foi construída por oito adolescentes grávidas, com faixa etária de 18 e 19 anos, o equivalente a quatro para cada idade. Em relação à etnia, quatro (50\%) eram da raça negra, três $(37,5 \%)$ se autodenominaram pardas e uma $(12,5 \%)$, branca. Quanto ao estado civil, cinco $(62,5 \%)$ eram solteiras e três $(37,5 \%)$ estavam em união estável. Em relação ao nível de escolaridade, variou do ensino fundamental completo ao ensino superior incompleto. Uma (12,5\%) gestante encontravase cursando o ensino superior, duas (25\%) concluíram o ensino médio, outras duas (25\%) relataram o ensino médio incompleto, uma (12,5\%) referiu ensino fundamental completo e duas (25\%) o ensino fundamental incompleto. Quanto à religião, todas $(100 \%)$ informaram ser católica. Em relação ao emprego remunerado, nenhuma relatou possuir. No que tange à moradia, seis (75\%) moram com os pais, e duas (25\%) residem com o companheiro. A renda familiar variou entre inferior a um salário mínimo até dois salários mínimos.

\section{Razões para engravidar e sentimentos vivenciados pelas adolescentes}

"Engravidei por falta de cuidados; confiei que outras vezes que fazia sem se prevenir não engravidei, aí continuava. Não foi falta de informação sobre anticoncepcional, não, porque eu conhecia... " (G2)

"Sabia das informações de como não engravidar, mas não me prevenia, achava que não ia acontecer comigo". (G3)

Verificou-se que as razões que levaram a essas adolescentes a engravidarem variaram desde a falta de contracepção, mesmo possuindo informações sobre os meios de evitar a gravidez, até a confiança de que não iria engravidar por haver uma grande prática de atividade sexual desprotegida.

Ainda no primeiro núcleo de sentido, destacou-se que, entre os sentimentos vivenciados, percebe-se que, passada a fase de descoberta de uma gravidez indesejada, as mães adolescentes passam a expressar bons sentimentos com relação ao filho:

"Me sinto a pessoa mais feliz do mundo, apesar de que não estava muito em meus planos. Eu me sinto realizada e que toda hora fico ansiosa e não vejo a hora da filha nascer, para dar amor e carinho." (G2)

"Estou alegre, mas, no inicio, foi bem dificil [...]”. (G8)

Acredita-se que adolescentes praticam atividade sexual desprotegida por causa de impulsos e desejos momentâneos, sem analisar suas consequências, acarretando, em muitos casos, uma gravidez indesejada, cheias de sentimentos de rejeição, tristeza e angústia, causando um grande impacto na vida psicológica desta adolescente, embora nem sempre enfrentadas dessa forma.

\section{Apoio familiar e profissional versus preconceito}

Conforme os discursos, as adolescentes revelaram o apoio por parte da mãe e do companheiro. 
"Sempre tive o apoio dos meus pais e do meu parceiro, claro que, no início, eles não receberam essa informação com muito entusiasmo. (...) Eles me ajudam comprando coisinhas pro bebê, me incentivando a comparecer às consultas, pois são importantes". (G1)

"Só tenho o apoio do meu companheiro e da minha mãe, porque a família me julga muito, foi bastante difícil. Mas hoje é a alegria de minha mãe". (G3)

Quanto à equipe multidisciplinar que assiste as adolescentes grávidas dentro da Estratégia Saúde da Família (ESF), foram citados os ACS, os médicos, os cirurgiões-dentistas e os enfermeiros como sendo os profissionais que mais se destacaram na assistência às gestantes, compreensível nas falas a seguir:

"A agente de saúde da minha comunidade e a enfermeira". (G1)

"[...], só tive mesmo da enfermeira". (G3)

"Eu tive do meu médico e da enfermeira, que sempre me atenderam”. (G4)

"O dentista, agente de saúde e a enfermeira me apoiam". (G5)

Nesta pesquisa, ao se questionar as adolescentes a respeito da existência de preconceitos, pôde-se perceber, pelos discursos, a sua ocorrência, tanto por parte da família quanto pela sociedade:

“Das pessoas mais velhas a gente sofre, das pessoas de fora, chamando de 'santinha do pau oco'. Eles comentam muito”. (G1)

"Algumas pessoas falam mal, mas eu não ligo. Meus amigos mesmo falam, me criticam por isso e me tratam com indiferença”. (G5)

"Do meu pai. Meu pai, no início, me criticava muito, reclamava sempre, dizia coisas horríveis. Ai, depois acabou aceitando e parou com essas coisas". (G6)

Neste contexto, percebe-se o quanto as adolescentes sentem-se intimidadas para abordar as questões que envolvem sexualidade, devido aos sentimentos de repreensão impostos pela sociedade. Quando a adolescente engravida, esses sentimentos impostos pela sociedade tendem a aflorar, intensificando os julgamentos e preconceitos.

\section{Mudanças positivas versus dificuldades enfrentadas}

Quanto às diversas mudanças ocorridas no período gestacional, ao referirem-se às mudanças positivas, as adolescentes citaram:

"Eu senti que as outras pessoas e a minha família, principalmente, ficaram mais cuidadosas, e eu vejo que elas querem me transmitir um sinal de apoio”. (G1)

"Com a gravidez fiquei mais próxima do meu companheiro, da maioria dos meus familiares e de certos amigos. Então, proximidade e aconchego foram os meus pontos positivos nesse inicio de gravidez”. (G3)

É notável nos discursos que houve uma maior aproximação da família e do companheiro dessas adolescentes, passando também a demonstrar maior cuidado e proteção.

Assim, em relação às dificuldades enfrentadas, as participantes do estudo mencionaram as seguintes:

"A dificuldade foi a questão que eu estou cursando faculdade de administração, $3^{\circ}$ semestre, e fico assustada por saber que vou ter que trancar [...] fico triste por isso...”. (G1)

"Estava estudando para o vestibular e, quando soube que estava grávida, parei o cursinho e não fiz o vestibular; dificuldade de arrumar um emprego”. (G4)

"As dificuldades foram por ter deixado meus estudos, porque eu sentia muito sono; gostava muito de sair, ir pras festas, me divertir com meu companheiro". (G5)

São perceptíveis nos relatos as dificuldades em levar a diante os estudos, além do incômodo sexual, entre outros desconfortos físicos, decorrentes do processo fisiológico da gestação, como se observa a seguir:

"Fazer relação com o companheiro, mesmo sabendo que relação na gravidez não prejudica a criança; sinto dificuldade de andar; bastante preguiça; dificuldade de dormir e dor nas costas". (G2)

"Na relação sexual causa um pouquinho de desconforto". (G3)

"A relação sexual, tenho menos vontade e fico com mais dificuldade por causa do desconforto”. (G5)

\section{DISCUSSÃO}

A gestação precoce pode acarretar mudanças significativas na vida de qualquer adolescente, independente das razões que 
a levaram a engravidar - seja pela falta de acesso aos métodos contraceptivos, seja por não compreenderem a real necessidade desses, seja ainda por acreditarem que essa não ocorrerá. Os sentimentos advindos desse período se mostram ambivalentes, iniciando-se com medo, angústia e rejeição, que se transformam, a partir de sua aceitação, em prazerosas emoções. Ressalta-se a amplitude desse fenômeno quando se evidencia que 15 a 20\% dos nascimentos são frutos de relacionamentos na adolescência nos países do Cone Sul. Dessa forma, constata-se, no Brasil e Paraguai, que na última década as adolescentes engravidaram cada vez mais cedo, apesar da observação do decréscimo da taxa de fecundidade em nível de Brasil ${ }^{(4)}$.

Uma pesquisa que investigou o perfil socioeconômico, demográfico, cultural, regional e comportamental da gravidez na adolescência no Brasil refere que as regiões Norte e Nordeste possuem taxas superiores à média nacional, de 55,5\% de mulheres que engravidaram antes dos 19 anos de idade ${ }^{(12)}$.

No que se refere ao perfil sociodemográfico das adolescentes grávidas participantes da presente investigação, resultados semelhantes foram identificados em outro trabalho ao investigar as transformações decorridas da gravidez de adolescentes. Tendo a média de idade apresentada de 19 anos, com média de escolaridade de oito anos e $77 \%$ das participantes não trabalhavam ${ }^{(13)}$.

Em outro estudo, os resultados referentes a adolescentes grávidas retrataram que a maioria completou a escola primária, porém $80 \%$ não deram continuidade em sua fase de vida escolar. Dessas, $94 \%$ eram mulatas e apenas $6 \%$ trabalhavam. $\mathrm{O}$ rendimento familiar predominava entre um a dois salários mínimos, mas, em contrapartida, a renda familiar era complementada por programas sociais de transferência de renda. Em consonância com o presente estudo, nota-se a prevalência da raça negra e um perfil econômico não elevado ${ }^{(14)}$.

Outra pesquisa revela que a gestação na adolescência se associa à baixa escolaridade, mesmo que de forma independente, pois essa associação encontrava-se mais presente ao fato de terem um parceiro e ao desejo e planejamento da gravide ${ }^{(15)}$.

Quanto à religião, todas as participantes da presente pesquisa referiram ser católicas. A religião tem forte influência na vida dos seres humanos, já que, em geral, regula o modo de agir e determina suas condutas morais. Porém, em um estudo realizado com adolescentes grávidas, notou-se que a ligação com a religião não foi forte o suficiente para fazer com que elas permanecessem virgens até o casamento. Isto demonstra que as adolescentes, embora inseridas em um grupo religioso, vivem e praticam sua sexualidade livremente, ainda que isto seja invisível aos olhos de seus responsáveis ${ }^{(16)}$.

No que concerne às razões para engravidar, resultados compatíveis aos analisados no presente estudo foram encontrados em outro estudo, no qual as adolescentes também detinham o conhecimento acerca da contracepção, mas não o suficiente para evitar uma gravidez precoce ${ }^{(14)}$.

Outros estudos nacionais realizados com grupos semelhantes demonstraram que as adolescentes, apesar de conhecerem os métodos contraceptivos, não compreendem sua importância. Tais práticas acabam por assumir um risco potencial de uma gravidez indesejada ao realizarem atividades sexuais desprotegidas ${ }^{(17)}$.

Em relação aos sentimentos vivenciados, a literatura evidencia que a descoberta da gravidez na adolescência traz à tona variados sentimentos, como o medo de dizer para a família, o receio da decepção dos pais, desespero, dúvida e incerteza diante da situação da maternidade ${ }^{(18)}$. Resultados semelhantes foram evidenciados em uma pesquisa realizada na região Nordeste com 14 gestantes adolescentes que também reforçaram a presença da ambiguidade de sentimentos existentes nesse período ${ }^{(19)}$. Frente a esses sentimentos vivenciados, a rede de apoio familiar e o companheiro têm como principal função elevar a autoestima e evitar maiores traumas psicológicos decorrentes das transformações oriundas de uma gestação na adolescência ${ }^{(20)}$.

É perceptível que a família é representada como um pilar de sustentação na vida da adolescente, pois o núcleo familiar transmite segurança, uma vez que as adolescentes necessitam de apoio financeiro para o sustento e apoio emocional para enfrentar as modificações e ainda para os cuidados com o bebê $\hat{~}^{(21)}$. O surgimento de uma gravidez indesejada na adolescência pode resultar em sentimentos diversos, decorrentes de suas expectativas em relação ao futuro ${ }^{(21)}$. Esses sentimentos são intensificados caso a adolescente não tenha a participação do pai do bebê e da família, sendo imprescindível uma rede social de apoio para minimizar as intercorrências que possam surgir durante a gestação ${ }^{(22)}$.

Observou-se que, no contexto de gravidez na adolescência, tanto os pais como os companheiros, ao saberem da gestação, manifestaram reações de felicidade, susto e medo. A reação de felicidade do companheiro foi de 76,6\%; a do pai, de 59,1\% e a da mãe, de $65,9 \%$, indicando que a gravidez em adolescentes é vista positivamente ${ }^{(23)}$. Percebeu-se uma ambivalência no que concerne aos sentimentos relacionados à descoberta da gravidez, por parte da família, tendendo a serem contraditórios, sendo inicialmente comuns os sentimentos de revolta e abandono, por se tratar de um acontecimento inesperado. No entanto, com o passar do tempo, ocorre a aceitação do fato, transformando sentimentos negativos em positivos ${ }^{(23)}$.

O apoio da família é de extrema importância para a adolescente grávida, pois proporciona o apoio emocional necessário para o enfrentamento da nova realidade e das intensas mudanças que irão ocorrer ${ }^{(21,22)}$. A existência do apoio social faz-se necessário, ao passo que compreende um processo dinâmico que consiste em todo suporte proporcionado pela família, marido/companheiro e a não rejeição por parte dos amigos e sociedade ${ }^{(24)}$. Em um estudo realizado em um município da região Sul do país, verificouse que, dentre oito adolescentes grávidas que participaram do estudo, todas citaram a mãe como principal fonte de apoio ${ }^{(25)}$.

Com o intuito de ampliar o suporte necessário a gestantes adolescentes, constitui-se como prioritária a efetividade de uma rede de apoio profissional para a garantia de um cuidado integral ao binômio mãe e bebê. Neste contexto, a ESF ao ser instituída teve 
como ponto importante o estabelecimento de uma equipe multiprofissional, composta por, no mínimo um médico, um enfermeiro, auxiliar ou técnico de enfermagem e os ACS, podendo ser acrescidos a essa composição os profissionais de saúde bucal ${ }^{(26)}$.

Os profissionais de saúde que compõem a ESF exercem uma importante função na vida dessas adolescentes que, independente de seu perfil sócioeconômico e cultural, buscam na equipe de saúde uma possibilidade de escuta e resolução de seu problema, desejando serem acolhidas, orientadas e compreendidas em suas necessidades. Deve-se estabelecer uma relação de confiança entre adolescente e profissional, permitindo que a adolescente grávida sinta-se amparada e respeitada para que uma boa assistência possa ser mantida ${ }^{(27)}$.

Contrapondo-se aos achados da presente investigação, identifica-se que, apesar da necessidade da criação de vínculo entre os profissionais da ESF e as adolescentes grávidas, ainda se tem na literatura uma lacuna que se expressa por meio da invisibilidade desses trabalhadores da saúde nos relatos de vida dessas mulheres ${ }^{(19)}$. Estudiosos, a partir de suas vivências profissionais com grupos de adolescentes em ambiente escolar, perceberam a ocorrência de dúvidas, medos, tabus e preconceitos a respeito da temática sexualidade em suas discussões, fazendo-se necessário uma maior articulação entre saúde e educação ${ }^{(28)}$.

Elencam dificuldades enfrentadas com o advento da gravidez na adolescência, pois ocorre uma rápida passagem da situação de filha para mãe. Nessa transição abrupta de mulher em formação para mulher-mãe, a jovem vivencia uma situação conflituosa ao se ver desafiada a assumir um maior grau de responsabilidade ${ }^{(29)}$. Existe uma relação de conflito de identidade, pois necessitam amadurecer de forma precoce, passam a assumir responsabilidades e deixam de lado vivências naturais da adolescência ${ }^{(21)}$.

No que tange às mudanças corporais, o período gestacional requer novas formas de equilíbrio diante das modificações próprias dessa fase. Essas alterações estão relacionadas aos ritmos metabólicos e hormonais e ao processo de integração da nova imagem corporal, que repercute na dimensão física e emocional, podendo afetar a sexualidade da gestante ${ }^{(30)}$.

Além disso, considera-se que essas adolescentes encontram-se em pleno período de formação educacional, e a gravidez pode acarretar um atraso, ou até mesmo a suspensão, das atividade escolares, ocasionando a diminuição dos níveis de escolaridade e inadequado grau de profissionalização $0^{(31)}$.

Diante de seu contexto, a gestação na fase da adolescência constitui-se um problema social e de saúde pública, o qual exige programas de orientação, preparação e acompanhamento durante todo o período gestacional, com seguimento durante o parto e puerpério, pois uma gestação nessa fase do ciclo vital oferece riscos ao desenvolvimento da criança, assim como para a própria adolescente grávida ${ }^{(32,33)}$, tornando-se primordial que os profissionais de saúde assumam uma atenção mais qualificada com essas gestantes ${ }^{(33)}$.

Frente ao exposto, desponta a necessidade de que se tenha em vista as ações para a promoção de saúde e consolidação de Políticas Públicas que visem o debate precoce sobre educação sexual e planejamento reprodutivo, unindo forças entre ambiente escolar e unidades de saúde ${ }^{(34,35)}$.

Ressalta-se ainda que este estudo não teve a pretensão de estabelecer uma generalização acerca das modificações psicossociais enfrentadas por adolescentes grávidas.

Percebe-se que ainda existem lacunas a serem exploradas no que diz respeito aos fatores psicossociais enfrentados por adolescentes grávidas, o que pode fomentar mais pesquisas dentro desse tema, lançando um novo olhar para essas mulheres, enfatizando não apenas a gestação, mas o suporte social por parte da família e profissionais da saúde. Dentre as limitações do estudo, destaca-se a não possibilidade de análise das repercussões psicossociais na fase inicial da adolescência.

\section{CONSIDERAÇÕES FINAIS}

Diante do objetivo proposto, emergiram como resposta para as modificações psicossociais enfrentadas pelas adolescentes grávidas do estudo sentimentos de rejeição, tristeza e angústia oriundos de uma gravidez indesejada, devido a um impacto na vida psicológica dessa adolescente, embora nem sempre enfrentada dessa forma.

Percebeu-se ainda nos relatos das adolescentes a presença da experiência da intimidação por parte da sociedade e dos familiares, oriundas dos julgamentos e preconceitos que afloraram no momento em que engravidou.

Quanto ao suporte familiar, as adolescentes citaram a mãe e o companheiro. No que se refere à equipe multidisciplinar da ESF, foram citados os ACS, os médicos, os agentes de saúde e os enfermeiros, sendo estes últimos o profissional mais aludido pelas participantes.

Destarte, torna-se necessário a construção de um plano de cuidados, por intermédio de discussões entre os profissionais de saúde e as adolescentes, sobre a melhor forma de assistir a gravidez nos serviços de saúde.

\section{REFERÊNCIAS}

1. Ministério da Saúde (BR), Secretaria de Atenção à Saúde. Marco legal: saúde, um direito de adolescentes. Brasília: Ministério da Saúde; 2007. (Série A. Normas e Manuais Técnicos)

2. Fernandes AO, Santos HPO Júnior, Gualda DMR. Gravidez na adolescência: percepções das mães de gestantes jovens. Acta Paul Enferm [Internet]. 2012 [acesso em 2015 Jul 22];25(1):55-60. Disponível em: http://www.scielo.br/scielo. 
php?script=sci_arttext\&pid=S0103-21002012000100010

3. Kerntopf MR, Lacerda JFE, Fonseca NH, Nascimento EP, Lemos ICS, Fernandes GP, et al. Sexualidade na adolescência: uma revisão crítica da literatura. Adolesc Saúde [Internet]. 2016 [acesso em 2017 Jun 2];13(Supl 2):106-13. Disponível em: http://www.adolescenciaesaude.com/detalhe_artigo.asp?id=590

4. Fundo de População das Nações Unidas. fecundidade e maternidade adolescente no cone sul: anotações para a construção de uma Agenda Comum 2016. Chile: Escritório Regional da América Latina e Caribe; 2016.

5. Organização das Nações Unidas Brasil - ONU Brasil. [Internet]. 2017 [acesso em 2017 Dez 24]. Disponível em: https:// nacoesunidas.org/brasil-tem-setima-maior-taxa-adolescente-da-amercia-do-sul/

6. Taborda JA, Silva FC, Ulbricht L, Neves EB. Consequências da gravidez na adolescência para as meninas considerando-se as diferenças socioeconômicas entre elas. Cad Saúde Colet (Rio J) [Internet]. 2014 [acesso em 2017 Dez 22];22(1):16-24. Disponível em: http://www.scielo.br/pdf/cadsc/v22n1/1414-462X-cadsc-22-01-00016.pdf

7. Carta de Ottawa. In: 1a . Conferência Internacional sobre Promoção da Saúde [Internet]. Ottawa; 1986. [acesso em 2017 Dez 24]. Disponível em: http://bvsms.saude.gov.br/bvs/publicacoes/carta_ottawa.pdf

8. Siegel, Rebecca S. et al. Adolescents, Pregnancy, and Mental Health. J Pediatr Adolesc Gynecol [Internet]. 2014 [acesso em 2017 Jan 20];27(3):138-50. Disponível em: http://www.jpagonline.org/article/S1083-3188(13)00294-5/fulltext

9. Minayo MCS. O desafio do conhecimento: pesquisa qualitativa em saúde. 14 ed. São Paulo: Hucitec; 2014.

10. Trad LAB. Grupos focais: Conceitos, procedimentos e reflexões baseadas em experiências com o uso da técnica em pesquisas de saúde. Physis (Rio J). 2009;19(3):777-96.

11. Ministério da Saúde (BR), Conselho Nacional de Saúde. Resolução nº 466, de 12 Dez. 2012. Diretrizes e normas regulamentadoras de pesquisas envolvendo seres humanos. Brasília: Ministério da Saúde; 2012.

12. Cruz MS, Carvalho FJV, Irffi G. Perfil socioeconômico, demográfico, cultural, regional e comportamental da gravidez na adolescência no Brasil. Rev Plan Pol Públicas. 2016;46:243-66.

13. Zanchi M, Kerber NPC, Biondi HS, Silva MR, Gonçalves CV. Teenage maternity: life's new meaning?. J Hum Growth Dev [Internet]. 2016 [acesso em 2017 Jan 14] 26(2):199-204. Disponível em: http://pepsic.bvsalud.org/scielo.php?script=sci_ab stract\&pid=S0104-12822016000200010

14. Menezes LMS, Delmontes LM, Vieira, IS. Demographic-socioeconomic profile and sexual behavior of pregnant adolescents in a city in northeastern Brazil. Acta Sci Health Sci [Internet]. 2016 [acesso em 2017 Jan 14];38(1):1-7. Disponível em: https:/www.researchgate.net/publication/304185504_Demographic-socioeconomic_profile_and_sexual_behavior_of_ pregnant_adolescents_in_a_city_in_northeastern_Brazil

15. Faisal-Cury A, Tabb KM, Niciunovas G, Cunningham C, Menezes PR, Huang H. Lower education among low-income brazilian adolescent females is associated with planned pregnancies. Int J Womens Health [Internet]. 2017 [acesso em 2017 Jun 14];9:43-8. Disponível em: https:/www.ncbi.nlm.nih.gov/pmc/articles/PMC5268373/

16. Assis MR, Silva LR, Pinho AM, Moraes LEO, Lemos A. Gravidez na adolescência e sua relação com a prática do sexo seguro. Rev Enferm UFPE On line. [Internet]. 2013 [acesso em 2017 Jan 14];7(4):1073-80. Disponível em: https://www. arca.fiocruz.br/handle/icict/6810

17. Silva MRB, Silva LA, Maturana HCA, Silva RB. Porque elas não usam? Um estudo sobre a não adesão das adolescentes ao preservativo e suas repercussões. Saúde Redes [Internet]. 2015 [acesso em 2017 Dez 25];1(4):75-83. Disponível em: revista.redeunida.org.br/ojs/index.php/rede-unida/article/viewFile/633/pdf_17

18. Munslinger IM, Silva SM, Bortoli CFC, Guimarães KB. A maternidade na perspectiva de mães adolescentes. Rev Bras Promoç Saúde [Internet]. 2016 [acesso em 2015 Nov 16];29(3):357-63. Disponível em: http://periodicos.unifor.br/RBPS/ article/view/4541

19. Lima FBN, Lira GG, Melo RA, Mola R, Fernandes FECV. Maternidade: significados atribuídos por adolescentes primíparas. Rev Enferm UFPE On line [Internet]. 2017 [acesso em 2015 Dez 26];11(3):1163-70. Disponível em: http://periodicos.ufpe. br/revistas/revistaenfermagem/article/download/13491/16212

20. Leite MP, Bohry S. Conflitos relacionados a gravidez na adolescência e a importância do apoio familiar. Encontro Rev Psicol (Valinhos. Online) [Internet]. 2012 [acesso em 2017 Dez 25];15(23):113-28. Disponível em: www.pgsskroton.com. br/seer/index.php/renc/article/download/2474/2370

21. Santos NLB, Guimarães DA, Gama CAP. A percepção de mães adolescentes sobre seu processo de gravidez. Rev Psicol Saúde [Internet]. 2016 [acesso em 2017 Dez 22];8(2):83-96. Disponível em: http://dx.doi.org/10.20435/2177-093X-2016v8-n2(07) 
22. Cremonese L, Wilhelm LA, Prates LA, Paula CC, Sehnem GD, Ressel LB. Apoio social na perspectiva da puérpera adolescente. Esc Anna Nery Rev Enferm [Internet]. 2017 [acesso em 2017 Dez 24];21(4):1-8. Disponível em: www.redalyc. org/pdf/1277/127752022012.pdf

23. Souza TA, Brito MEM, Frota AC, Nunes JM. Gravidez na adolescência: percepções, comportamentos e experiências de familiares. Rev Rene [Internet]. 2012 [acesso em 2015 Nov 16];13(4):794-804. Disponível em: http://www.redalyc.org/ articulo.oa? id=324027983009

24. Alves RD, Oliveira SX, Caldas MLLS, Nobre JOC. Dificuldades enfrentadas por adolescentes no período gestacional. Temas Saúde [Internet]. 2016 [acesso em 2017 Dez 25];16(2):585-66. Disponível em: http://temasemsaude.com/wp-content/ uploads/2016/08/16230.pdf

25. Santos CC, Wilhelm LA, Alves CN, Cremonese L, Castiglioni CM, Venturini L, et al. A vivência da gravidez na adolescência no âmbito familiar e social. Rev Enferm UFSM [Internet]. 2014 [acesso em 2016 Dez 25];4(1):105-12. Disponível em: http://periodicos.ufsm.br/reufsm/article/download/9860/pdf

26. Ministério da Saúde (BR), Secretaria de Atenção de Atenção à Saúde, Departamento de Atenção Básica. Atenção ao prénatal de baixo risco. Brasília: Ministério da Saúde; 2013.

27. Oliveira MP, Cruz NM, Moura LA, Moura JG, Coelho RMN, Melo MCP. Cuidado às adolescentes grávidas: perspectivas e atuação de agentes comunitários de saúde. Rev Enferm UERJ [Internet]. 2015 [acesso em 2016 Fev 20];23(1):76-81. Disponível em: http://www.e-publicacoes.uerj.br/index.php/enfermagemuerj/article/view/15580

28. Santos CL, Sabóia VM. Sexualidade e saúde na adolescência: relato de experiência. Academus. [Internet]. 2017 [acesso em 2017 Dez 20];2(1):1-9. Disponível em: http://smsrio.org/revista/index.php/reva/article/download/256/263

29. Moreira MA, Nascimento ER, Paiva MS. Representações sociais de mulheres de três gerações. Texto \& Contexto Enferm [Internet]. 2013 [acesso em 2017 Dez 26];22(2):432-41. Disponível em: http://www.scielo.br/pdf/tce/v22n2/v22n2a20.pdf

30. Araújo NM, Salim NS, Gualda DMR, Silva LCFP. Corpo e sexualidade na gravidez. Rev Esc Enferm USP [Internet]. 2012 [acesso em 10 Fev 2016];46(3):552-8. Disponível em: http://www.scielo.br/pdf/reeusp/v46n3/04.pdf

31. Pinto JF, Oliveira VJ, Souza MC. Perfil das adolescentes grávidas no setor saúde do município de Divinópolis - Minas Gerais. Rev Enferm Cent.-Oeste Min [Internet]. 2013 [acesso em 22 Dez 2017];3(1):518-530. Disponível em: http://www. seer.ufsj.edu.br/index.php/recom/article/view/289

32. Araújo RLD, Nóbrega AL, Nóbrega JYL, Silva GS, Sousa KMO, Coelho DC, et al. Gravidez na adolescência: consequências voltadas para a mulher. INTESA [Internet]. 2015 [acesso em 2016 Dez 26];9(1):15-22. Disponível em:

33. Araujo RLD, Rodrigues ESRC, Oliveira GG, Sousa KMO. Gravidez na adolescência: consequências centralizadas para a mulher. Temas Saúde [Internet]. 2016 [acesso em 2017 Dez 25];16(2):567-87. Disponível em: http://temasemsaude.com/ wp-content/uploads/2016/08/16231.pdf

34. Sena VLM Filha, Castanha AR. Profissionais de unidade de saúde e gravidez na adolescência. Psicol Soc. 2014;26(Esp):79-88.

35. Santos NLB, Guimarães DA, Gama CAP. A percepção de mães adolescentes sobre seu processo de gravidez. Rev Psicol Saúde [periódico da Internet]. 2016 [acesso 2017 Dez. 26]; 8(2):83-96. Disponível em: http://dx.doi.org/10.20435/2177093X-2016-v8-n2(07)

\section{Endereço do primeiro autor:}

Gleiciane Fontenele Costa

Instituto Superior de Tecnologia Aplicada - INTA

Rua Cel. Antônio Rodrigues Magalhães, 359

Bairro: Dom Expedito Lopes

CEP: 62050-100 - Sobral - CE - Brasil

E-mail: gleicyy_fc@hotmail.com

\section{Endereço para correspondência:}

Francisca Alanny Araújo Rocha

Instituto Superior de Tecnologia Aplicada - INTA

Rua Cel. Antônio Rodrigues Magalhães, 359

Bairro: Dom Expedito Lopes

CEP: 62050-100 - Sobral - CE - Brasil

E-mail: alannyrocha2009@hotmail.com 